\title{
A Hybrid Assessment Method for Evaluating the Performance of Starting Pitchers in a Professional Baseball Team
}

\author{
Chih-Cheng Chen ${ }^{1}$ Yung-Tan Lee $^{2}$ Chung-Ming Tsai ${ }^{3}$ \\ ${ }^{1}$ Department of Sport Management, Aletheia University, 25103, Taiwan \\ ${ }^{2}$ Department of Tourism, Aletheia University, 25103, Taiwan \\ ${ }^{3}$ Department of Management Science, National Chiao Tung University, 30050, Taiwan
}

\begin{abstract}
The performance assessment of professional baseball starting pitchers is considered a multi-attribute decisionmaking (MADM) problem. This study develops an evaluation model based on the analytic hierarchy process (AHP) and grey relational analysis (GRA) to evaluate starting pitcher performance for teams of the Chinese Professional Baseball League. The AHP is used to determine attribute weights, whereas the GRA calculates the individual grey relational degree. We conducted an empirical analysis to show the use of the model for addressing the starting pitcher performance problem. The results demonstrate the effectiveness and feasibility of the proposed model.
\end{abstract}

Keywords: Starting pitchers, AHP, GRA, Chinese Professional Baseball League

\section{Introduction}

Throughout the history of baseball, starting pitchers were considered more crucial than players in other positions [1-2]. Starting pitchers pitch more innings over the course of a season, and, for a century, all of the best pitchers in teams were starting pitchers [1-2]. The manager and coaches on a professional baseball team are chiefly concerned about the starting pitcher. Managers or coaches determine the performance of starting pitchers using the number of innings pitched, strikeouts, and games won or lost [1,3]. Evaluating the performance of professional starting pitchers is therefore a complex decisionmaking problem that includes several quantitative attributes. It is regarded as a type of multi-attribute decision-making (MADM) problem [1, 3]. Several common methodologies were proposed for resolving this MADM, such as the technique for order preference by similarity to ideal solution (TOPSIS), the analytical hierarchy process (AHP), data envelopment analysis (DEA), and grey relational analysis (GRA) [3-4]. MADM methodologies have been successfully applied to various professional baseball problems, such as using the AHP to evaluate professional baseball players on a Major League Baseball team [5]. Other examples include using GRA to evaluate the contribution of starting pitchers in a professional baseball team [6], integrated AHP and TOPSIS methods for selecting the best starting pitcher [1], and arranging the rotation for starting pitchers [3].

In a comprehensive evaluation of the performance of a complex system (such as the performance of starting pitchers in a professional baseball team), indicators used for evaluation should generally be correlated and not independent of each other. This condition accords with the 
characteristics of a "grey system" [6]. Grey system theory, proposed by Deng, has been widely applied to various fields $[4,6]$. It is useful for managing inferior, incomplete, and uncertain information. GRA is part of grey system theory, which is suitable for solving problems with complex interrelationships between multiple factors and variables $[4,6]$. GRA was successfully applied to solve various MADM problems, including hiring, supplier selection, and athlete evaluation [7]. In theory, the grey relational analysis method assumes that the importance of all performance attributes is equal. In practice, a decision maker who considers the importance of performance attributes as not equal judges an MADM problem. This study applied the AHP to determine the weight of each attribute for performance measurement. The AHP provides decision makers with a way to transform subjective judgments into objective measurements, and has been used to determine attribute weights in many MADM problems [8]. This study proposes an integrated AHP and GRA approach to assess MADM within professional baseball teams.

\section{Methodology}

\subsection{Analytical Hierarchy Process method}

The AHP is one of the most extensively used MADM methods. We applied the AHP to determine the weight of each criterion for performance measurement. The procedure typically involves several steps, including defining the unstructured problem, stating the objectives before determining the relative weights of the decision elements, and obtaining an overall rating for the alternatives [8]. We used several steps to determine attributes weights: (1) establish a pairwise compari- son matrix; (2) estimate the relative weights of the decision elements; and (3) test for the consistency of the judgment matrix.

\subsection{Grey Relational Analysis method}

GRA is based on the degree of similarities or differences of development trends between an alternative and the ideal alternative. A stronger relationship exists if the trend of change between the alternative and the ideal alternative is consistent; otherwise, the relational grade is smaller [4, 6-7]. Using GRA, the first step is to translate the performance of each alternative into a comparability sequence. This step is called "grey relational generating." A reference sequence (ideal target sequence) is defined according to these sequences. Subsequently, the grey relational coefficient between all comparability sequences and the reference sequence is calculated. Finally, the grey relational grade between the reference sequence and each comparability sequence is calculated based on these grey relational coefficients. If a comparability sequence translated from an alternative has the highest grey relational grade between the reference sequence and itself, that alternative is the optimal choice [4]. This study used several steps to determine the grey relational grade: Step1 was grey relational generating; Step2 was reference sequence definition; Step3 was grey relational coefficient calculation; and Step4 was grey relational grade calculation.

\subsection{Data}

The data used in this study were obtained from the official CPBL website (http://www.cpbl.com.tw), which collected and posted records of every CPBL baseball game in 2012. We selected alternatives for the winning team in 2012 from the official CPBL website in 2012. Every alternative chosen has played at 
least one game as a starting pitcher for his team. The commonly cited statistics for starting pitchers found in the empirical analysis were innings pitched (IP), games won (Wins), games lost (Lost), and the number of opponent batter outs induced (outs) $[1,3,6]$, all of which are included in this study. The calculation was performed using the AHP and GRA, in which parameters used as attributes are familiar to all fans.

\section{Empirical analysis for evaluating the performance of starting pitchers}

\subsection{Alternative pitchers' pitching in- formation}

In the interest of the Chinese Professional Baseball League players, actual player names could not be used in this paper. A brief description of 15 pitchers is provided. Code names of pitchers in the CPBL are listed in Table 1. As shown in Table 1, all starting pitchers started more than two games in the 2012 season. The analysis indicated that A2 was the player with the best performance, having started 25 games, won 15 games, pitched 170.1 innings, and made 497 outs. A1 was second best. However, others were not clearly discriminated.

Table 1 Alternative starting pitchers' pitching information

\begin{tabular}{|c|c|c|c|c|c|}
\hline Player & GS & Wins & Lost & IP & Outs \\
\hline A1 & $27(1)$ & $12(2)$ & $5(14)$ & $166.2(2)$ & $473(2)$ \\
\hline A2 & $25(2)$ & $15(1)$ & $7(15)$ & $170.1(1)$ & $497(1)$ \\
\hline A3 & $10(3)$ & $5(3)$ & $2(6)$ & $42.2(4)$ & $125(4)$ \\
\hline A4 & $9(4)$ & $3(5)$ & $4(11)$ & $53.2(3)$ & $160(3)$ \\
\hline A5 & $8(5)$ & $4(4)$ & $2(6)$ & $37.1(5)$ & $107(5)$ \\
\hline A6 & $7(6)$ & $0(11)$ & $4(11)$ & $26.2(8)$ & $74(8)$ \\
\hline A7 & $6(7)$ & $0(11)$ & $3(9)$ & $28(7)$ & $88(7)$ \\
\hline A8 & $5(8)$ & $2(7)$ & $1(2)$ & $35(6)$ & $106(6)$ \\
\hline A9 & $5(8)$ & $0(11)$ & $3(9)$ & $20.1(9)$ & $60(9)$ \\
\hline A10 & $4(10)$ & $3(5)$ & $1(2)$ & $19.1(10)$ & $57(10)$ \\
\hline A11 & $4(10)$ & $1(8)$ & $2(6)$ & $9(13)$ & $27(13)$ \\
\hline A12 & $3(12)$ & $0(11)$ & $1(2)$ & $14.1(12)$ & $46(12)$ \\
\hline A13 & $3(12)$ & $1(8)$ & $0(1)$ & $16(11)$ & $52(11)$ \\
\hline A14 & $2(14)$ & $1(8)$ & $1(2)$ & $6(15)$ & $16(15)$ \\
\hline A15 & $2(14)$ & $0(11)$ & $2(6)$ & $7.1(14)$ & $22(14)$ \\
\hline
\end{tabular}

\subsection{Using the AHP to determine weights of evaluation attributes}

Two ex-professional baseball team managers and two coaches, one Taiwanese baseball team coach, and two experts contributed their professional experience to determine the relative importance of the four individual performance measures: wins, losses, innings pitched, and outs. The AHP determined the weights of the evaluation attributes. We used a questionnaire to obtain opinions from managers, coaches, and experts. A sample question used was, "Which performance measures should receive more emphasis in determining starting pitcher attributes, and how much more?" A 9-point scale permitted pairwise comparisons. Eight questionnaires were returned, and each one passed a consistency test. Using all the questionnaire results, we calculated the geometric mean for all pairwise comparisons for each manager, coach, and expert. Table 2 shows the results. We then calculated the eigenvector and eigenvalue of the table.

Table 2 Comparison matrix

\begin{tabular}{|c|c|c|c|c|}
\hline & Wins & Lost & IP & Outs \\
\hline Wins & 1.00 & 1.72 & 0.90 & 1.23 \\
\hline Lost & 0.58 & 1.00 & 0.33 & 0.45 \\
\hline IP & 1.12 & 3.00 & 1.00 & 0.66 \\
\hline Outs & 0.82 & 2.23 & 1.51 & 1.00 \\
\hline
\end{tabular}

The eigenvector shows the weights of the different criteria. Results indicate that the Wins criterion, with a weight of .299, is the major factor in determining starting pitcher performance in the CPBL; the second is the Outs criterion (.288); the third is the Innings Pitched criterion (.255); and the Lost criterion (.158) is the fourth.

\subsection{GRA for alternative pitchers}

Based on the data in Table 1, the GRA procedure is conducted as follows. First, we performed grey relational generating. The main purpose of grey relational gen- 
erating is to transfer the original data into comparability sequences. Lost was considered a cost attribute, and Wins, IP, and Outs were benefit attributes. Second, we ran a grey relational coefficient calculation. Lastly, we used a relational grade calculation. In this case, the importance of all performance attributes was weighted differently. The weights of the four performance attributes were $0.3, .16, .26$ and .29 . The grey relational grade can be calculated as shown in Column 2 of Table 3.

Table 3 The results of grey relational analysis

\begin{tabular}{|c|c|c|}
\hline Player & Grey Relational Grade & Ranking \\
\hline A1 & 0.784 & 2 \\
\hline A2 & 0.895 & 1 \\
\hline A3 & 0.441 & 4 \\
\hline A4 & 0.414 & 8 \\
\hline A5 & 0.429 & 7 \\
\hline A6 & 0.370 & 15 \\
\hline A7 & 0.385 & 12 \\
\hline A8 & 0.438 & 5 \\
\hline A9 & 0.377 & 14 \\
\hline A10 & 0.430 & 6 \\
\hline A11 & 0.388 & 11 \\
\hline A12 & 0.411 & 9 \\
\hline A13 & 0.452 & 10 \\
\hline A14 & 0.408 & 13 \\
\hline A15 & 0.382 & 3 \\
\hline
\end{tabular}

\section{Conclusion}

The evaluation of the performance of starting pitchers is a difficult problem that can be classified as a type of MCDM problem for managers or coaches of professional baseball teams. This study first applied the AHP to calculate criterion weights to determine who will be the best performing starting pitcher. GRA was then used to calculate the performance of each starting pitcher candidate with respect to each criterion. Finally, the AHP and GRA were used to calculate the ranks of all starting pitchers for a team in CPBL. At the end of a baseball season, this methodology can be used to provide team managers and coaches with a thorough understanding of the performance of starting pitchers in their team.

\section{References}

[1] C.C. Chen, M.L. Lin, Y.T. Lee, T.T. Chen, and C.L. Huang, "Selection Best Starting Pitcher of the Chinese Professional Baseball League in 2010 Using AHP and TOPSIS Methods", Advances in Intelligent and Soft Computing, vol. 133, pp. 643-649, 2012.

[2] M. Lewis, Moneyball: The Art of Winning an Unfair Game. New York: Norton, 2003.

[3] C.C. Chen, M.L. Lin, Y.T. Lee, and T.T. Chen, "Starting Pitcher Rotation in the Chinese Professional Baseball League based on AHP and TOPSIS", Proceeding of World Academy of Science, Engineering and Technology, vol. 58, pp. 74-79, 2011.

[4] Y. Kuo, T. Yang, and G.W. Huang, "The use of grey relational analysis in solving multiple attribute decisionmaking problems", Computers \& Industrial Engineering, vol. 55, pp. 8093, 2008.

[5] L. Bodin, "Why the New York Yankees Signed Johnny Damon ", in Perspectives in Operations Research, 36, Alt, F.B., Fu, M.C., and Golden, B.L. New York: Springer US, 2006, pp. 415-428.

[6] C.C. Chen, Y.T. Lee, S.Y. Lee, S.K. Huang, T.T. Chen, and Q.J. Chen, "Evaluation of the Contribution of Starting Pitchers in a Professional Baseball Team by Grey Relational Analysis", International Journal of Social and Human Sciences, vol. 6, pp. 195-198, 2012a.

[7] N. Slavek, and A. Jović, "Heptathlon evaluation model using Grey system theory ", Tehnicki Vjesnik, vol. 19, pp. 327-331, 2012.

[8] R.S. Guo, D.M. Chiang, and F.Y. Pai, "Multi-objectives exception management model for semiconductor back-end environment under turnkey service", Production Planning \& ControlVolume, vol. 18, pp. 203-216, 2007. 